\title{
Avaliação do impacto ambiental da integração lavoura-pecuária: Aspecto conservação ambiental no cerrado ${ }^{1}$
}

\author{
Caroline A. Galharte ${ }^{2} \&$ Silvio Crestana ${ }^{3}$
}

RESUMO

\begin{abstract}
As atividades agrícola e pecuária são geradores de resíduos e, potencialmente, produtores de impactos ambientais, como qualquer outra atividade humana. A remediação e a avaliação dos impactos ambientais são necessidades imperiosas para sustentabilidade de uma atividade e proteção dos ecossistemas. Com o intuito de suprir tais necessidades, a Empresa Brasileira de Pesquisa Agropecuária (EMBRAPA) produziu um instrumento de avaliação de impacto ambiental da inovação tecnológica agropecuária, denominado Ambitec-A gro. Dentre inúmeras inovações tecnológicas selecionou-se a Integração lavoura-pecuária, que visa recuperar áreas de lavouras degradadas, usar eficientemente a terra, recuperar e renovar pastagens degradadas, ou seja, promover sustentabilidade agropecuária. 0 presente trabalho propôs, por meio de estudo de caso, avaliar os impactos promovidos pela inovação tecnológica do binômio integrado lavoura-pecuária em área irrigada e de sequeiro, com o uso do AmbitecAgro. A avaliação do impacto ambiental da Integração lavoura-pecuária no aspecto consenvação ambiental foi satisfatória, visto que se obtiveram índices positivos e significativos em relação à qualidade da água, qualidade do solo e biodiversidade no âmbito do estabelecimento estudado.
\end{abstract}

Palavras-chave: indicadores, qualidade do solo, qualidade da água, biodiversidade, Ambitec-Agro

\section{The assessment of the environmental impact of agriculture-animal husbandry integration: Environmental conservation aspect in 'Cerrado'}

\begin{abstract}
The practice of agriculture and cattle raising produces waste, and as a result it can create environmental impacts. Therefore, it is necessary to assess, predict, and lessen the environmental impact for the sustainability of this activity and protection of ecosystems with the intention to fulfil such needs, the Brazilian Agricultural Research Agency (EM BRAPA) has proposed a system, the Environmental Impact Assessment of Agricultural Technology Innovations (Ambitec-Agro). Among countless technological innovations, the agriculture animal husbandry integration was selected which aims to improve the production of farming products in deteriorated areas; intensifying the use of land; and reclaming and renovating agricultural areas and pastures to guarantee agricultural sustainability. Based on a case study, this work aimed to make the assessment of the environmental impact caused by technology innovation of the animal husbandry integration in unirrigated and irrigated areas by applying the A mbitec-Agro system. The assessment of the environmental impact of animal husbandry integration, in the environmental conservation aspect was satisfactory, thus significative and positive indices were obtained in relation to water quality, soil quality and biodiversity in the scope of the studied establishment.
\end{abstract}

Key words: indicators, soil quality, water quality, biodiversity, Ambitec-Agro

\footnotetext{
1 Parte da Dissertação de Mestrado do primeiro autor apresentada à Escola de Engenharia de São Carlos/Universidade de São Paulo

2 Departamento de Hidráulica e Saneamento/U SP, CP 292, CEP 13.560-970, São Carlos, SP. Fone: (16) 3373-8253. E-mail: gal harte@sc.usp.br

3 Embrapa CN PDIA, Rua XV de Novembro 1452, Centro, CEP 13560-970, São Carlos, SP. Fone: (16) 2107-2800. E-mail: crestana@cnpdia.embrapa.br
} 


\section{INTRODUÇÃO}

O principal atalho para uma nação alcançar o desenvolvimento é utilizar de modo adequado, utilizar seu potencial científico para gerar inovações tecnológicas (Crestana, 2004). Nos últimos anos o agronegócio brasileiro apresentou excelente desempenho entre os setores econômicos nacionais, motivo pelo qual é denominado "Âncora Verde" do plano de estabilização econômica e das políticas macroeconômicas do governo (Crestana \& Silva, 2006).

Apesar dos setores da pecuária e agricultura possuírem grande importância na economia brasileira e contarem com pesquisa e infraestrutura, ainda é fato que solos marginais (periféricos) são destinados aos cultivos de pastagens e lavouras que, consequentemente, favorecem o processo de degradação das propriedades físicas, químicas e biológicas do solo cenário que compromete a sustentabilidade do ecossistema.

Para reverter este cenário, uma opção interessante é a Integração lavoura-pecuária, que consiste na rotação lavoura/pecuária e resulta em maior eficiência produtiva, com vantagens para ambas as atividades. A Integração lavoura-pecuária, principalmente quando associada ao sistema plantio direto, proporciona inúmeros benefícios ao produtor e ao ambiente, como: agregação de valores; redução dos custos de produção relacionados ao controle de pragas, doenças e plantas invasoras e recuperação das propriedades produtivas do solo; sendo assim, a inovação tecnológica promove a recuperação/renovação de pastagens degradadas e recuperação de lavouras degradadas, ou seja, uso eficiente da terra.

A unidade amostral selecionada neste trabalho está localizada em um dos principais biomas brasileiros, o Cerrado, com mais de 200 milhões de hectares - segunda maior área, que corresponde a $24 \%$ da área total do Brasil - possui importantes características, como: nascente de grandes bacias hidrográficas brasileiras (Amazônica, Tocantis-Araguaia, São Francisco e Paraná-Paraguai); abundância de luminosidade; pequena variação da temperatura durante todo o ano e bom regime pluvial por seis a sete meses durante o ano. Esses fatores permitem a exploração intensiva de culturas anuais e pastagem o ano todo condição ideal para a Integração lavoura-pecuária; esta escolha é justificada diante da perspectiva de aumento na demanda global por alimentos e o sistema de Integração lavoura-pecuária pretende consolidar o Cerrado como grande produtor de leite, carne, grãos e energia. O melhor aproveitamento da agropecuária na produção de alimentos diminuirá a pressão para a abertura de novas áreas. Ressalta-se que o sistema Integração lavoura-pecuária propicia alto rendimento no ganho de peso vivo por hectare (Assmann et al., 2004).

O objetivo principal deste trabalho é apresentar dados das avaliações de impactos da Integração lavoura-pecuária em área irrigada e de sequeiro, no Cerrado, referente ao aspecto conservação ambiental que diz respeito aos recursos naturais: atmosfera, solo, água e biodiversidade.

\section{MATERIAL E MÉTODOS}

Conforme Macedo (2009) a Integração lavoura-pecuária possibilita a produção de grãos, fibras e carne em uma mesma área, em plantio simultâneo, sequencial ou rotacionado. O sistema visa maximizar o uso dos ciclos biológicos das plantas e dos animais, juntamente com seus respectivos resíduos; minimizar o uso de agroquímicos; aumentar a eficiência no uso de máquinas, equipamentos e mão-de-obra; gerar emprego e aumentar a renda dos trabalhadores rurais, preceitos que visam diminuir os impactos ambientais e sociais, em referência à sustentabilidade.

Segundo Kluthcouski et al. (2000), o sistema Santa Fé, tecnologia desenvolvida na Embrapa Arroz e Feijão, se fundamenta na produção consorciada de culturas de grãos, especialmente milho, sorgo, arroz, soja e milheto, com forrageiras tropicais de preferência do gênero $\mathrm{Bra}$ chiaria, no sistema de plantio direto, em áreas de Integração lavoura-pecuária, com solo parcial ou devidamente corrigido.

O estudo foi realizado na Fazenda Capivara, sede da Embrapa Arroz e Feijão, localizada no Município de Santo Antônio de Goiás, estado de Goiás, por adotar o sistema de Integração lavoura-pecuária em uma área de aproximadamente 92 ha, dos quais 54 são, atualmente, de pastagem, e o restante é ocupado por culturas. Nesta área a implantação da pastagem é feita via Sistema Santa Fé (milho + braquiária); o pasto (braquiária) é usado para o pastejo de touros da raça Nelore, que fazem parte de um programa de melhoramento genético.

O quadrante 4 do pivô central, Figura 1, localizado na Fazenda Capivara, foi escolhido como espaço amostral para avaliação de impacto ambiental da Integração lavoura-pecuária em área irrigada.

Justifica-se a escolha deste quadrante devido a um histórico completo, antes e depois da adoção do sistema Integração lavoura-pecuária além de consórcio de culturas anuais com forrageira, em relação aos outros três quadrantes, conforme a Tabela 1.

Para avaliação de impacto ambiental da Integração lavoura-pecuária em área de sequeiro foi escolhido como cenário o mesmo ecossistema que compôs o espaço amostral da Fazenda Capivara; entretanto, por se tratar de sistema de sequeiro, substituiu-se a cultura do feijão irrigado, tanto no inverno do ano de 2005 quanto no inverno do ano de 2006, por restos vegetais sendo possível obter dados para avaliar o impacto da Integração lavoura-pecuária nessas condições.

Para este trabalho foram entrevistados treze pesquisadores da EMBRAPA, que trabalham com Integração lavoura-pecuária no Cerrado, empregando a metodologia do Ambitec-Agro, com foco no aspecto conservação ambiental, com os seguintes indicadores: qualidade do solo 


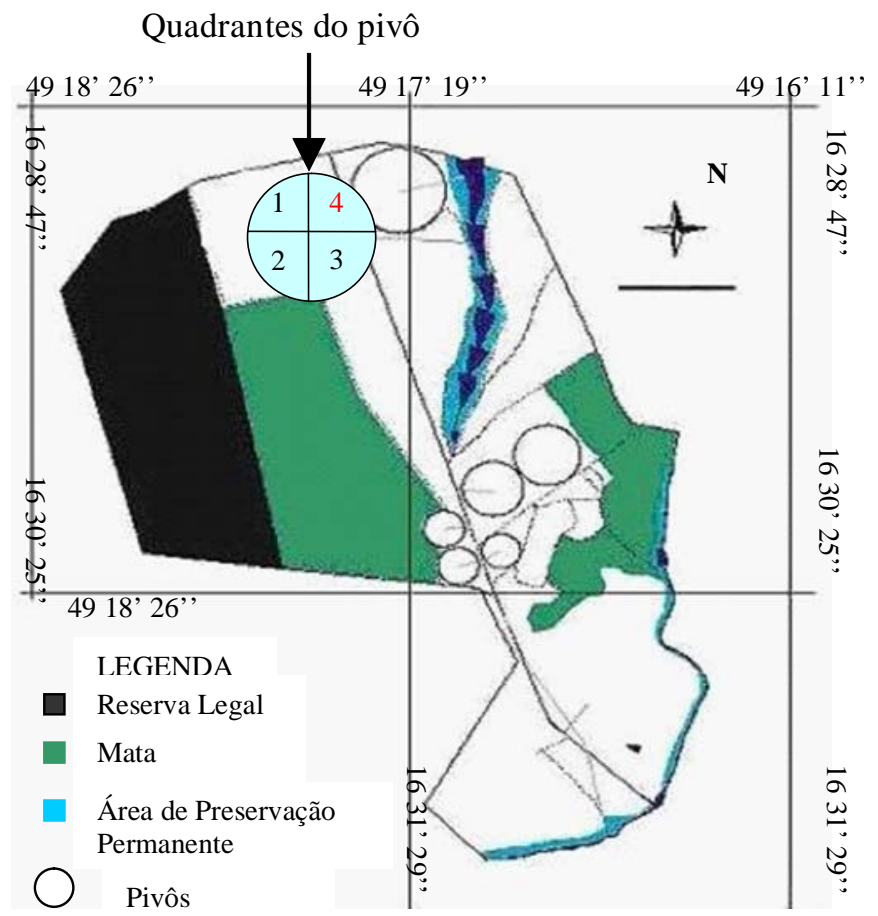

49 17' 19',

49 16' 11",

Figura 1. Mapa da estrutura física da Fazenda Capivara (Fonte: Adaptado de Embrapa Arroz e Feijão, 2006)

Tabela 1. Histórico da rotação de culturas do pivô central da Fazenda Capivara

\begin{tabular}{|c|c|c|c|c|c|}
\hline \multirow{2}{*}{ Ano } & \multirow{2}{*}{ Época } & \multicolumn{4}{|c|}{ Quadrante } \\
\hline & & 1 & 2 & 3 & 4 \\
\hline \multirow[t]{2}{*}{1993} & Inverno & Feijão & Feijão & Feijão & Feijão \\
\hline & Verão & Soja & Soja & Soja & Soja \\
\hline \multirow[t]{2}{*}{1994} & Inverno & Feijão & Feijão & Feijão & Feijão \\
\hline & Verão & Soja & Soja & Soja & Soja \\
\hline \multirow[t]{2}{*}{1995} & Inverno & Feijão & Feijão & Feijão & Feijão \\
\hline & Verão & Milho & Milho & Milho & Milho \\
\hline \multirow[t]{2}{*}{1996} & Inverno & Feijão & Feijão & Feijão & Feijão \\
\hline & Verão & Milho & Milho & Milho & Milho \\
\hline \multirow[t]{2}{*}{1997} & Inverno & Feijão & Feijão & Feijão & Feijão \\
\hline & Verão & Milho & Milho & Milho & Milho \\
\hline \multirow[t]{2}{*}{1998} & Inverno & Feijão & Feijão & Feijão & Feijão \\
\hline & Verão & Soja & Soja & Soja & Soja \\
\hline \multirow[t]{2}{*}{1999} & Inverno & Feijão & Feijão & Feijão & Feijão \\
\hline & Verão & Milho & Milho & - & Milho \\
\hline \multirow[t]{2}{*}{2000} & Inverno & Soja & Feijão & - & Feijão \\
\hline & Verão & Feijão & Soja & - & Soja \\
\hline \multirow[t]{2}{*}{2001} & Inverno & Cevada & Cevada & - & Cevada \\
\hline & Verão & Milho+ Capim & Milho+ Capim & Milho+ Capim & Milho+ Capim \\
\hline \multirow[t]{2}{*}{2002} & Inverno & Capim & Feijão & Capim & Capim \\
\hline & Verão & Capim & Soja & Capim & Capim \\
\hline \multirow[t]{2}{*}{2003} & Inverno & Capim & Crotalária & Capim & Capim \\
\hline & Verão & Capim & Milho+ Capim & Soja & Capim \\
\hline \multirow[t]{2}{*}{2004} & Inverno & Capim & Feijão & Feijão & Capim \\
\hline & Verão & Capim & Milho & Arroz & Soja \\
\hline \multirow[t]{2}{*}{2005} & Inverno & Capim & Feijão & Feijão & Feijão \\
\hline & Verão & Soja & Soja & Milho+Capim & Arroz \\
\hline 2006 & Inverno & Feijão & Milheto & Capim & Feijão \\
\hline
\end{tabular}

(erosão, perda de matéria orgânica, perda de nutrientes e compactação); qualidade da água (demanda bioquímica de oxigênio, turbidez, espuma/óleo/materiais flutuantes, sedimento e assoreamento), biodiversidade (perda de vegetação nativa, perda de corredores de fauna, perda de espécies e variedades caboclas) e atmosfera (gases de efeito estufa, material particulado/fumaça, odores e ruídos). O intuito nessas entrevistas era obter os coeficientes de alteração dos componentes de cada indicador de impacto referentes ao sistema de sequeiro e de área irrigada do bioma Cerrado.

O sistema Ambitec-Agro, desenvolvido por pesquisadores da Embrapa Meio Ambiente, propõe avaliar impactos ambientais de inovações tecnológicas agropecuárias, através de uma plataforma prática de execução simples, baixo custo e passível de aplicação a todo o universo tecnológico e ambiental de inserção institucional (Irias et al., 2004).

O objetivo da metodologia é promover o desenvolvimento sustentável pela adoção de inovações tecnológicas que minimizem os impactos negativos sobre a qualidade do ambiente e favoreçam o resgate do atual passivo ambiental da agricultura brasileira (Irias et al., 2004).

Conforme Rodrigues et al. (2003), o sistema AmbitecAgro envolve três etapas: na primeira, são feitos levantamento e coleta de dados gerais, por meio de material bibliográfico, sobre a tecnologia e o segmento do agronegócio ao qual ela se aplica, incluindo-se informações sobre o alcance da tecnologia (abrangência e influência), a delimitação da área geográfica e o universo dos adotantes da tecnologia; na segunda etapa se realizam entrevistas individuais com os adotantes/usuários selecionados e, a posteriori, se inserem dados sobre os indicadores de impacto nas planilhas eletrônicas desenvolvidas em plataforma MS-Excel, para então se obter resultados quantitativos dos impactos, os coeficientes de impactos e o índice agregado de impacto ambiental da tecnologia selecionada; na última etapa se procede à análise e interpretação desses índices, tal como indicação de alternativas de manejo da tecnologia para minimizar impactos negativos e potencializar os impactos positivos, contribuindo para o desenvolvimento local sustentável.

$\mathrm{Na}$ execução da avaliação se solicita, ao adotante/responsável, que indique a direção (aumento, diminuição ou manutenção) dos coeficientes de alteração dos componentes que variam de $(-3)$ a $(+3)$, dependendo da intensidade do efeito observado, apresentado na Tabela 2.

Em todas as matrizes de ponderação há uma linha exclusiva na qual o avaliador deve inserir a letra $\mathrm{X}$, caso o componente do indicador avaliado não se aplique na inovação tecnológica.

Os coeficientes de alteração são inseridos em matrizes de ponderação dos seguintes aspectos e seus respectivos indicadores: Eficiência tecnológica (uso de agroquímicos, uso de energia e uso de recursos naturais), conservação ambiental (atmosfera, qualidade do solo, qualidade da água e biodiversidade) e recuperação ambiental (recuperação ambiental). Ressalta-se que cada indi- 
Tabela 2. Efeitos da inovação tecnológica e coeficientes de alteração do componente a serem inseridos nas células das matrizes de avaliação de impacto ambiental da inovação tecnológica

Efeito da tecnologia na atividade sob as condições de manejo específicas do componente

Grande aumento no componente

Moderado aumento no componente

Coeficiente de alteração

Componente inalterado

Moderada diminuição no componente

Grande diminuição no componente

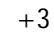

$+1$

0

$-1$

$-3$ cador possui seus componentes referentes; ao total, são avaliados trinta e sete componentes distribuídos nos oito indicadores, acima citados (Monteiro \& Rodrigues, 2006).

Nas matrizes automáticas se incluem também dois fatores de ponderação: um se refere à importância do componente para a formação do indicador e o outro à escala geográfica de ocorrência da alteração no componente, Tabela 3 .

Tabela 3. Matriz de ponderação do indicador biodiversidade fatores de ponderação e escala de ocorrência - Ambitec-Agro

\begin{tabular}{|c|c|c|c|c|c|c|}
\hline \multicolumn{7}{|c|}{ Tabela de coeficientes de alteração da variável } \\
\hline \multirow{2}{*}{\multicolumn{3}{|c|}{ Biodiversidade }} & \multicolumn{3}{|c|}{ Variável de Biodiversidade } & \multirow[b]{2}{*}{$\begin{array}{l}\text { Averiguação } \\
\text { fatores de } \\
\text { ponderação }\end{array}$} \\
\hline & & & $\begin{array}{l}\text { Perda de } \\
\text { vegetação } \\
\text { nativa }\end{array}$ & $\begin{array}{l}\text { Perda de } \\
\text { corredores } \\
\text { de fauna }\end{array}$ & $\begin{array}{l}\text { Perda de } \\
\text { espécies / } \\
\text { Variedades } \\
\text { caboclas }\end{array}$ & \\
\hline \multicolumn{3}{|c|}{ Fatores de ponderação k } & $-0,4$ & $-0,3$ & $-0,3$ & -1 \\
\hline \multicolumn{3}{|c|}{ Sem efeito Marcar com X } & - & - & - & - \\
\hline \multirow{3}{*}{$\begin{array}{l}\text { Escala da } \\
\text { ocorrência } \\
\quad=\end{array}$} & Pontual & 1 & - & - & - & - \\
\hline & Local & 2 & - & - & - & - \\
\hline & Entorno & 5 & -3 & -3 & -3 & - \\
\hline \multicolumn{3}{|c|}{$\begin{array}{c}\text { Coeficiente de impacto }= \\
\text { (coeficientes de alteração } * \text { fatores de } \\
\text { ponderação) }\end{array}$} & 6 & 4,5 & 4,5 & 15,0 \\
\hline
\end{tabular}

Os valores de importância dos componentes podem ser alterados pelo usuário do Ambitec-Agro com o intuito de otimizar a reflexão de certos componentes, isto é, enfatizá-los, desde que o valor total de todos os componentes seja igual à unidade $( \pm 1$, a depender da direção do impacto do indicador, se positivo ou negativo) (Rodrigues et al., 2006). Neste trabalho se optou por manter os valores originais dos fatores de ponderação relativos à importância dos componentes.

A escala da ocorrência explicita o espaço no qual se processa a alteração nos componentes do indicador, conforme a situação específica de aplicação da tecnologia sendo a) pontual, quando os efeitos da tecnologia no componente se restringem apenas ao local de sua ocorrência ou à unidade produtiva na qual ocorre a alteração - fator de ponderação igual a um; b) local, quando os efeitos se fazem sentir externamente ao local de ocorrência ou à unidade produtiva, porém confinados aos limites do estabelecimento - fator de ponderação igual a dois e c) no entorno, quando os efeitos se fazem sentir além dos limites do estabelecimento - fator de ponderação igual a cinco.

Após se inserir os coeficientes de alteração em cada célula dos componentes, a matriz de ponderação calcula o coeficiente de impacto do componente relativizada por fatores de ponderação devido à escala da ocorrência da alteração e ao peso do componente na composição do indicador. Os coeficientes de impacto dos componentes são somados para finalmente, gerarem o coeficiente de impacto do indicador que, por sua vez, pode variar entre os valores de $-15 \mathrm{a}+15$, dependendo do impacto gerado pela tecnologia, passível de ser positivo ou negativo.

\section{RESULTADOS E DISCUSS ÃO}

Nas Figuras 2A (referente à área de sequeiro) e 2B (diz respeito à área irrigada) estão apresentadas as médias dos coeficientes de impacto ambiental referentes aos componentes: erosão, perda de matéria orgânica, perda de nu-

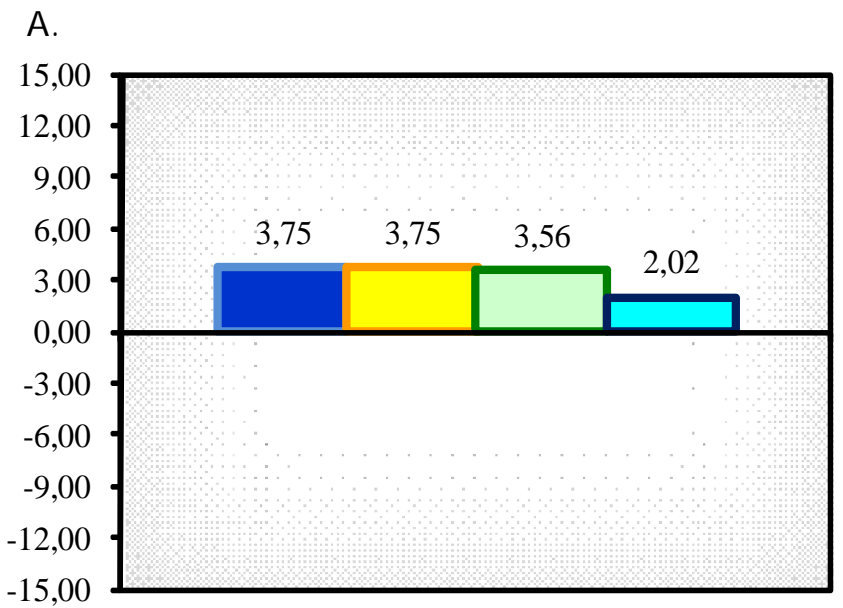

B.

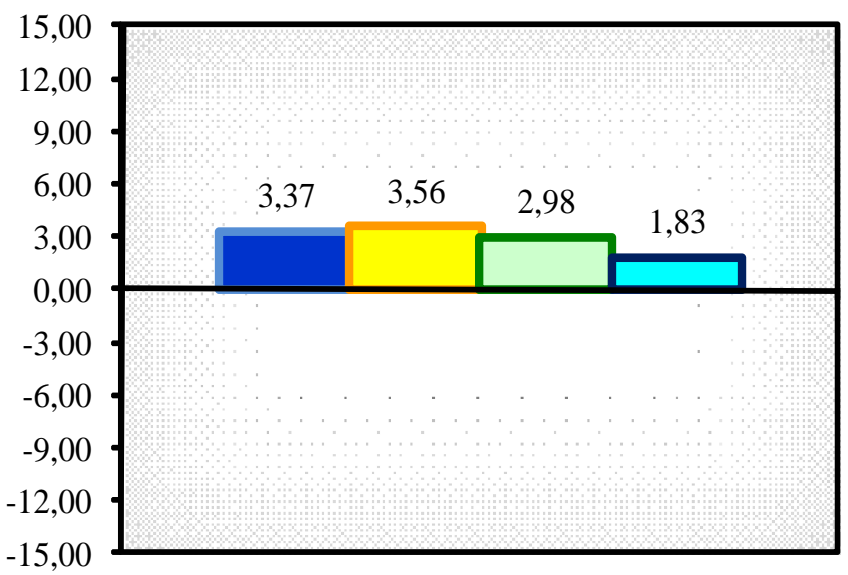

- Erosão

- Perda de Nutrientes

Perda de matéria Orgânica DCompactação

Figura 2. Componentes do indicador qualidade do solo em área de sequeiro (A) e em área irrigada (B) 
trientes e compactação, que pertencem ao indicador qualidade do solo.

As médias do coeficiente de impacto do componente erosão da Integração lavoura-pecuária em área de sequeiro $(\bar{\mu} ; \mu=3,75)$ e em área irrigada $(\bar{\mu} ; \mu=3,37)$ são próximas e positivas, Figuras $2 \mathrm{~A}$ e $2 \mathrm{~B}$, respectivamente. A inovação tecnológica Integração lavoura-pecuária associada ao sistema plantio direto, pressupõe a constante existência de cobertura do solo, tanto por gramíneas forrageiras quanto palhada, fato que propicia a redução da erosão. As gramíneas forrageiras são consideradas uma das espécies mais úteis para a conservação do solo; a parte aérea forma uma espécie de capa protetora que cobre toda a camada superficial do solo protegendo-o contra o impacto direto das gotas de chuva ou da radiação solar. Além disso, o sistema radicular fasciculado retém as partículas do solo; em consequência, é praticamente nula a perda do solo por erosão (Stone et al., 2003).

$\mathrm{Na}$ avaliação de impacto ambiental da Integração lavoura-pecuária em área de sequeiro e em área irrigada foi possível observar que a inovação tecnológica reduziu a perda de matéria orgânica, conforme apresentadas as médias dos coeficientes do componente Perda de Matéria Orgânica $(\bar{\mu} ; \mu=3,75$ em área de sequeiro e $\bar{\mu} ; \mu=3,56$ em área irrigada), Figuras 2A e Figura 2B, respectivamente. A Integração lavoura-pecuária propicia o uso limitado de fertilizantes e corretivos nas pastagens; assim, a necessidade de nutrição é naturalmente suprida, o que é feito pela matéria orgânica presente no solo.

Kluthcouski \& Stone (2003) afirmaram que as braquiárias produzem quantidade significativa de matéria seca, caso as condições de temperatura e umidade de solo sejam favoráveis; eles observaram, também, que os teores de matéria orgânica são mais altos em solo com pastagem de braquiária que em Cerrados virgens. O sistema de plantio direto contribui diretamente para o aumento da matéria orgânica, haja vista que não há operação de aração e gradagem, que reduzem o conteúdo orgânico do solo e propiciam perda da estrutura, da capacitação de nutrientes e água. A cobertura vegetal é responsável por impedir a exposição do solo, que oxida a matéria orgânica.

A diminuição da perda de nutrientes pode ser notada, com a adoção da Integração lavoura-pecuária em área de sequeiro e área irrigada, pois possuem médias de coeficientes de impactos positivos, $(\bar{\mu} ; \mu=3,56 \mathrm{em}$ área de sequeiro e $\bar{\mu} ; \mu=2,98$ em área irrigada), Figuras $2 \mathrm{~A}$ e $2 \mathrm{~B}$ respectivamente.

O uso do sistema integrado de lavoura com pastagem permite o uso desses resíduos como cobertura para semeadura direta da cultura que possibilita o aumento da reciclagem de nutrientes no sistema, devido ao mínimo revolvimento do solo e à manutenção da palhada. Além disso, os animais em pastejo agregam, por meio das fezes e urinas, nutrientes para as plantas (Lang et al., 2004).

Nas Figuras 2A e 2B é possível observar que entre os quatro componentes do aspecto Qualidade do Solo, o indicador Compactação é o que apresenta as menores médias dos coeficientes de impacto $(\bar{\mu} ; \mu=2,02$ em área de sequeiro e $\bar{\mu} ; \mu=1,83$ em área irrigada), pois alguns entrevistados consideraram moderada diminuição do componente.

No sistema Integração lavoura-pecuária o processo de compactação do solo pode ser induzido pelo pisoteio bovino, causando resistência do solo à penetração, a macroporosidade e a infiltração de água. Lanzanova et al. (2007) afirmam que no sistema de Integração lavoura-pecuária sob sistema plantio direto, se deve ter cuidado no manejo do pastejo para que não se perca a qualidade dos atributos físicos do solo. Ao avaliar diversos sistemas de manejo, os autores verificaram que eles não influenciaram na taxa de infiltração de água no solo após a cultura de milho, em virtude do elevado aporte e da manutenção de resíduos culturais na superfície do solo.

$\mathrm{Na}$ Figura 3A (referente à área de sequeiro) e 3B (referente à área irrigada) se apresentam as médias dos coeficientes de impacto ambiental concernentes aos componentes: demanda bioquímica de oxigênio, turbidez e

A.

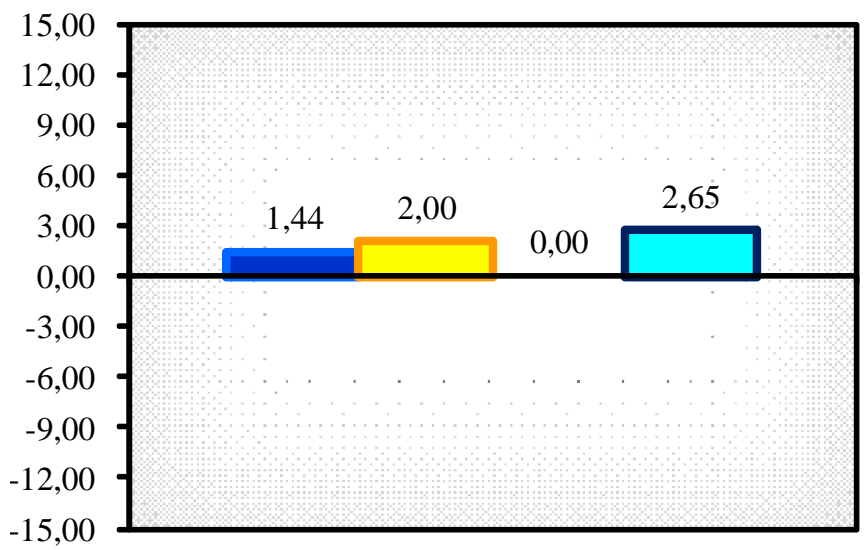

B.

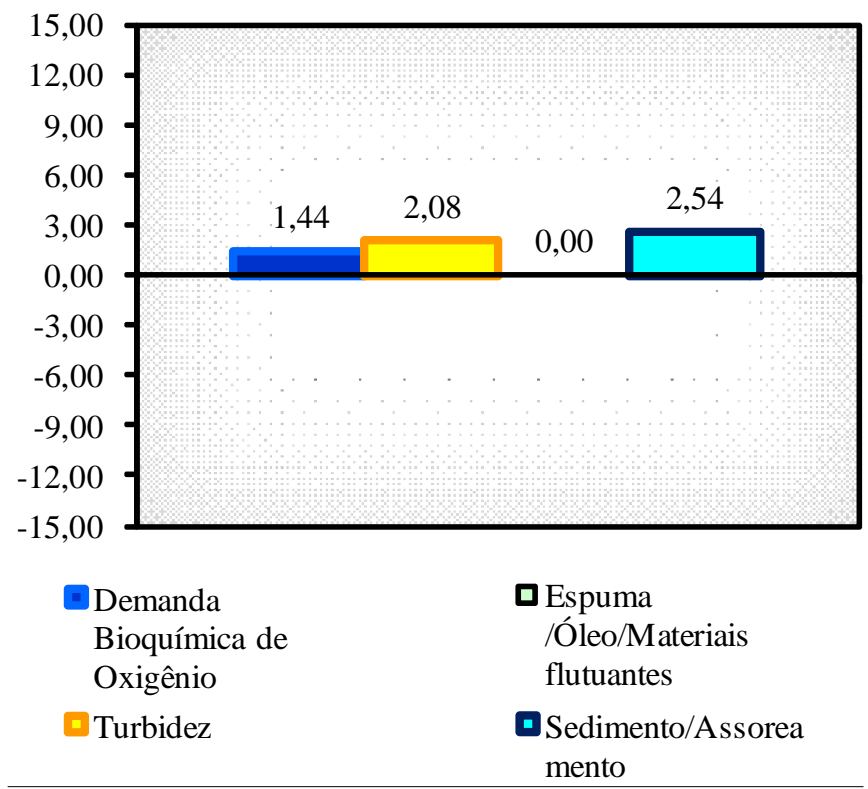

Figura 3. Componentes do indicador qualidade da água em área de sequeiro $(A)$ e em área irrigada (B) 
sedimento/assoreamento, que pertencem ao indicador qualidade da água, para as áreas de sequeiro e irrigada.

Os componentes demanda bioquímica de oxigênio $(\bar{\mu} ; \mu=1,44$ em área de sequeiro e em área irrigada), turbidez $(\bar{\mu} ; \mu=2,00 \mathrm{em}$ área de sequeiro e $\bar{\mu} ; \mu=2,08$ em área irrigada) e sedimento/assoreamento $(\bar{\mu} ; \mu=2,65$ em área de sequeiro e $\bar{\mu} ; \mu=2,54 \mathrm{em}$ área irrigada) do indicador Qualidade de Água são correlacionados. A diminuição significativa da erosão com a adoção da Integração lavoura-pecuária agregada ao sistema de plantio direto é a principal razão dos coeficientes de impacto dos componentes serem positivos, Figuras 3A e 3B. Com ausência de erosão, conforme discutido no indicador Qualidade do Solo, não há o assoreamento de corpo de água, nem a presença de sólidos em suspensão na água, sejam partículas orgânicas ou inorgânicas que comprometem a qualidade da água e, consequentemente, diminuem a demanda bioquímica de oxigênio.

Brito et al. (2005) afirmam que a aplicação de medidas de preservação e a conservação de recursos hídricos e dos solos, com manejo adequado do sistema solo-águaplanta, permitem a sustentabilidade ambiental.

A.

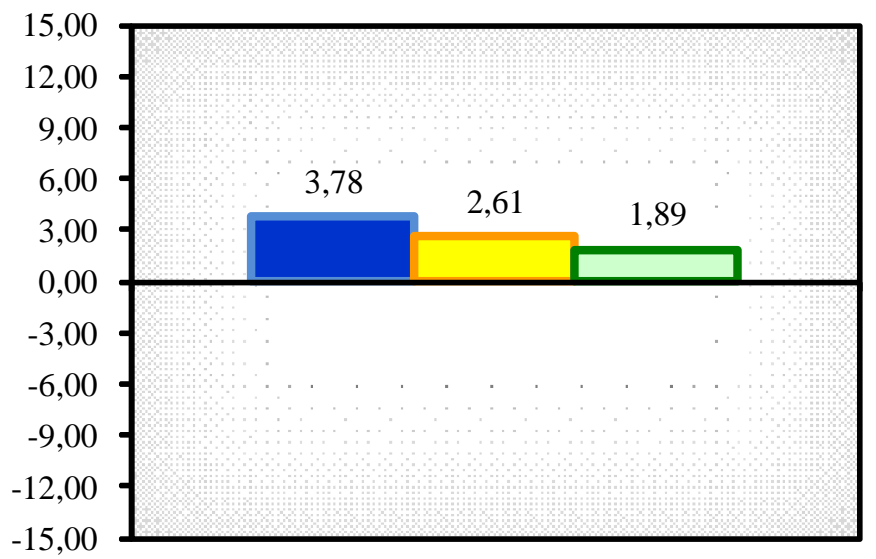

B.

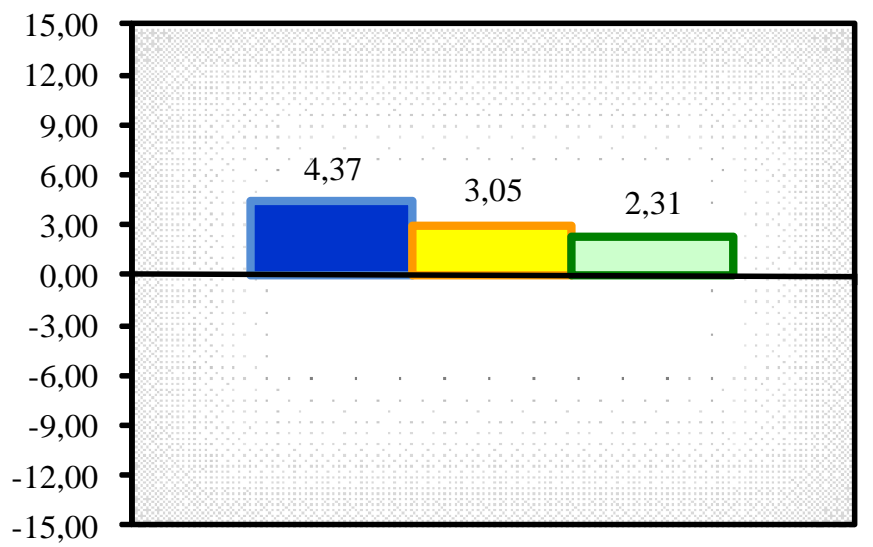

$\begin{array}{lll}\text { Perdade vegetação } & \begin{array}{l}\text { Perdade } \\ \text { nativa }\end{array} & \begin{array}{l}\text { Perdade } \\ \text { espécies/variedades } \\ \text { fauna }\end{array} \\ & \text { caboclas }\end{array}$

Figura 4. Componentes do indicador biodiversidade em área de sequeiro $(A) e$ em área irrigada (B)
Nas Figuras 4A (referente à área de sequeiro) e 4B (referente à área irrigada) se apresentam as médias dos coeficientes de impacto ambiental concernentes aos componentes: perda de vegetação nativa, e perda de corredores de fauna, perda de espécies/variedades caboclas, que pertencem ao indicador biodiversidade, para a área de sequeiro e área irrigada.

A diminuição das perdas de vegetação nativa $(\bar{\mu} ; \mu=3,78$ em área de sequeiro e $\bar{\mu} ; \mu=4,37$ em área irrigada) e da perda de espécies / variedades caboclas ( $\bar{\mu}$ up $8 ; \mu=1,89$ em área de sequeiro e $\bar{\mu} ; \mu=2,31$ em área irrigada), Figuras $4 \mathrm{~A}$ e $4 \mathrm{~B}$, contribuem para a conservação da área protegida; da mesma forma como a diminuição da perda dos corredores de fauna $(\bar{\mu} ; \mu$ $=2,61$ em área de sequeiro e $\bar{\mu} ; \mu=3,05$ em área irrigada), Figura $4 \mathrm{~A}$ e $4 \mathrm{~B}$, permite que tais áreas promovam a conexão entre áreas de preservação permanente existentes na propriedade e no seu entorno, cujos dados sugerem que a inovação tecnológica Integração lavoura-pecuária pode contribuir positivamente para a conservação dos habitats e da biodiversidade.

A.

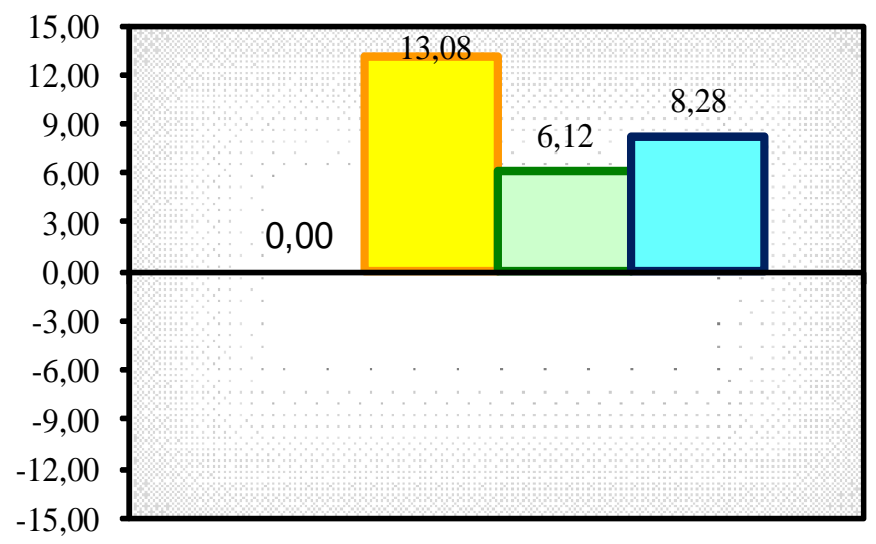

B.

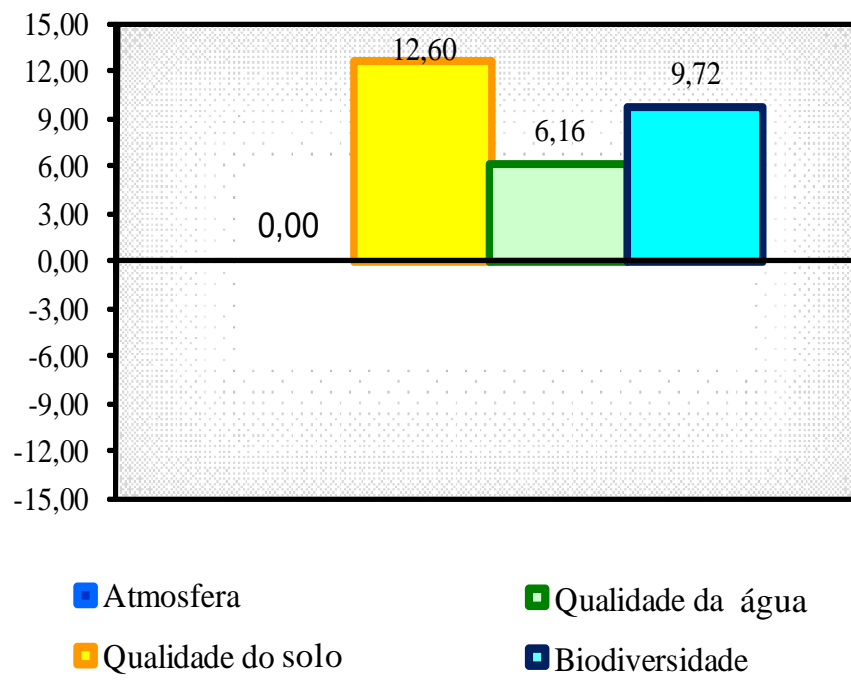

Figura 5. Indicadores agregados de conservação e qual idade ambiental em área de sequeiro (A) e em área irrigada (B) 
Nas Figuras 5A (alude à área de sequeiro) e Figuras 5B (relativas à área irrigada) estão apresentadas as médias dos coeficientes de impacto ambiental referentes aos indicadores: qualidade do solo, qualidade da água e biodiversidade em área de sequeiro e área irrigada.

$\mathrm{O}$ indicador atmosfera, Figuras $5 \mathrm{~A}$ e $5 \mathrm{~B}$, possuem os seguintes componentes: gases de efeito estufa, material particulado/fumaça, odores e ruídos; durante a realização das entrevistas neste trabalho, grande parte dos pesquisadores entrevistados afirmou não haver uma base firme de conhecimento que permita orientar o impacto que o sistema Integração lavoura-pecuária causa na atmosfera, isto é, o indicador atmosfera não foi avaliado em virtude da hesitação dos entrevistados em valorarem o componente gases de efeito estufa.

Os coeficientes de impactos dos indicadores qualidade do solo $(\bar{\mu} ; \mu=13,08$ em área de sequeiro e $\bar{\mu} ; \mu=12,60 \mathrm{em}$ área irrigada); qualidade da água ( $\bar{\mu} ; \mu=6,12 \mathrm{em}$ área de sequeiro e $\bar{\mu} ; \mu=6,16$ em área irrigada) e biodiversidade $(\bar{\mu} ; \mu=8,28$ em área de sequeiro e $\bar{\mu} ; \mu=9,72$ em área irrigada), Figuras 5A e 5B, respectivamente, são positivos e significativos; desta forma, esses dados sugerem que a inovação tecnológica Integração lavoura-pecuária pode contribuir positivamente para a conservação dos recursos e da biodiversidade fundamentais para a sustentabilidade das atividades agropecuárias.

\section{CONCLUSÕES}

1. Com a adoção da Integração lavoura-pecuária, ocorre diminuição da erosão que contribui para a conservação da qualidade do solo e também da qualidade da água.

2. A intensificação do uso do solo por meio das atividades agrícola e pecuária em uma mesma área pode possibilitar a diminuição da pressão da abertura de novas áreas que, consequentemente, podem ter sua biodiversidade conservada.

3. As avaliações de impacto realizadas na Fazenda Capivara (Sede Administrativa da Embrapa Arroz e Feijão localizada em Santo Antonio de Goiás, GO) tanto em área irrigada quanto em sequeiro, foram valoradas de forma positiva, ou seja, contribuem para a minimização de impactos negativos.

\section{AGRADECIMENTOS}

Os autores agradecem ao Conselho Nacional de Desenvolvimento Científico e Tecnológico (CNPq) pela bolsa de Mestrado; ao Programa de Pós-graduação em Ciências da Engenharia Ambiental, EESC-USP, à Embrapa e aos pesquisadores entrevistados.

\section{LITERATURA CITADA}

Assmann, A. L.; Pelissari, A.; Moraes, A.; Assmann, T. S.; Oliveira, E. B.; Sandini, I. Produção de gado de corte e acúmulo de matéria seca em sistema de integração lavoura-pecuária em presença e ausência de trevo branco e nitrogênio. Revista Brasileira de Zootecnia, v.33, n.1, p.37-44, 2004.

Brito, L. T. de L.; Srinivasan, V. S.; Silva, A. de S.; Gheyi, H. R.; Galvão, C. de O.; Hermes, L. C. Influência das atividades antrópicas na qualidade das águas da Bacia Hidrográfica do Rio Salitre. Revista Brasileira de Engenharia Agrícola e Ambiental, v.9, n.4, p.596-602, 2005.

Crestana, S. Inovação e desenvolvimento: Faces da mesma moeda. Revista Inovação, v.1, p.28-30, 2004.

Crestana, S.; Silva, R. C. O impacto da pesquisa no desenvolvimento do agronegócio brasileiro. In: Congresso Brasileiro de Soja, 4, 2006, Londrina. Anais... Londrina: Embrapa Soja, 2006. CD-Rom.

Irias, L. J. M.; Gebler, L.; Palhares, J. C. P.; Rosa, M. F.; Rodrigues, G. S. Avaliação de impacto de inovação tecnológica agropecuária - aplicação do sistema ambitec. Agricultura em São Paulo, v.51, n.1, p.23-39, 2004.

Kluthcouski, J.; Cobucci, T.; Aidar, H.; Yokoyama, L. P.; Oliveira, I. P.; Costa, J. L. S; Silva, J. G.; Vilela, L.; Barcellos, A. O.; Magnabosco, C. U. Sistema Santa Fé - Tecnologia Embrapa: Integração lavoura-pecuária pelo consórcio de culturas anuais com forrageiras, em áreas de Integração lavoura-pecuária, nos sistemas direto e convencional. Santo Antônio de Goiás: Embrapa Arroz e Feijão, 2000. 28p. Circular Técnica.

Kluthcouski, J.; Stone, L. F. Manejo sustentável dos solos dos cerrados. In: Kluthcouski, J.; Stone, L. F.; Aidar, H. (ed.) Integração lavoura-pecuária. Santo Antônio de Goiás: Embrapa Arroz e Feijão, 2003. cap.3, p.59-104.

Lang, C. R.; Pelissari, A.; Moraes, A. de; Sulc, R. M.; Oliveira, E. B. de; Carvalho, P. C. de F. Fitomassa aérea residual da pastagem de inverno no sistema Integração lavoura-pecuária. Scientia Agraria, v.5, n.1-2, p.43-48, 2004.

Lanzanova, M. E.; Nicoloso, R. da S.; Lovato, T.; Eltz, F. L. F.; Amado, T. J. C.; Reinert, D. J. Atributos físicos do solo em sistema de Integração lavoura-pecuária sob plantio direto. Revista Brasileira de Ciência do Solo, v.31, n.5, p.1131-1140, 2007.

Macedo, M. C. M. Integração lavoura e pecuária: o estado da arte e inovações tecnológicas. Revista Brasileira de Zootecnia, v.38, p.133-146, 2009.

Monteiro, R. C.; Rodrigues, G. S. A system of integrated indicators for socio-environmental assessment and eco-certification in agriculture: Ambitec-Agro. Journal of Technology Management \& Innovation, v.1, p.47-59, 2006.

Rodrigues, G. S.; Campanhola, C.; Kitamura, P. C. An environmental impact assessment system for agricultural R \& D. Environmental Impact Assessment Review, v. 23, n.1, p. 219244, 2003. 
Rodrigues, G. S.; Rodrigues, I. A.; Camargo, O. T. A. C.; Novo, A. L. M.; Bonadio, L. F.; Takuda, F. S.; Andrade, E. F.; Shiota, C. M., Silva, R. A. Avaliação sócio-ambiental da integração tecnológica Embrapa Pecuária Sudeste para produção leiteira na agricultura familiar. Agricultura em São Paulo, v.53, n.2, p.35-48, 2006.
Stone, L. F.; Moreira, J. A. A.; Kluthcouski, J. Influência das Pastagens na Melhoria dos atributos físico-hídrico do solo. In: Kluthcouski, J.; Stone, L. F.; Aidar, H. (ed.) Integração lavoura-pecuária. Santo Antônio de Goiás: Embrapa Arroz e Feijão, 2003. cap.6, p.171-181. 